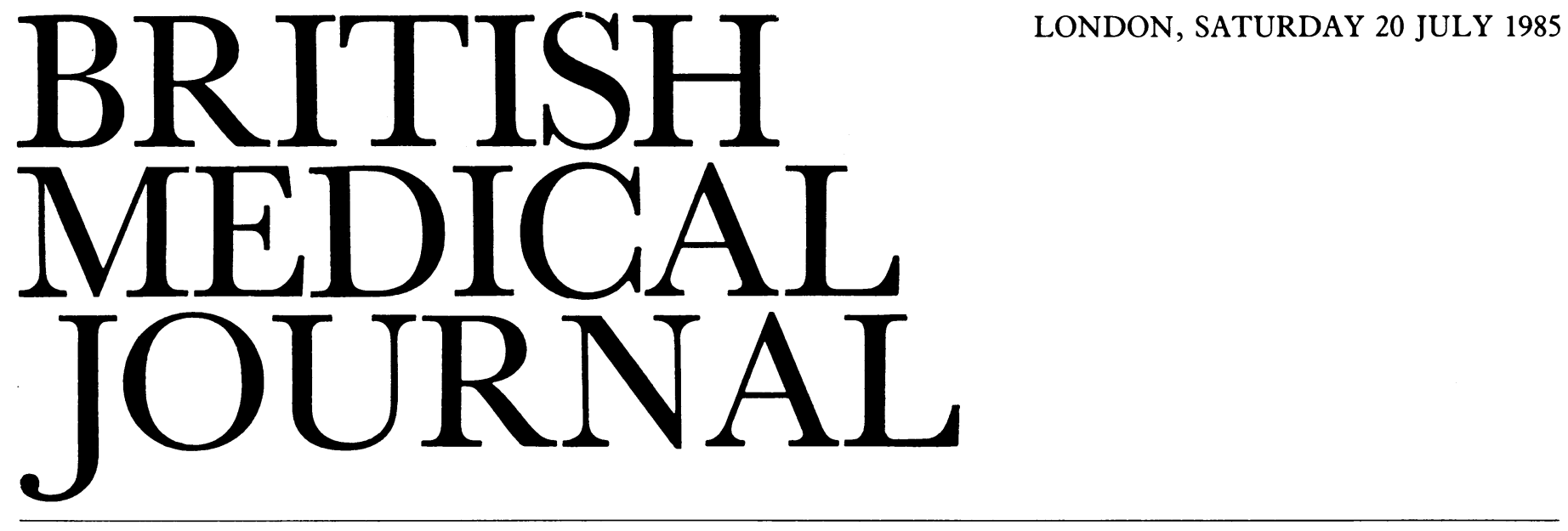

\title{
Nuclear medicine and the nursing mother
}

When nuclear medicine investigations are requested for women who are breast feeding they present a potential hazard to the infant both from radiation and from pharmaceuticals transmitted in the breast milk. Cases have been described of babies drinking radioactive milk and more have probably gone unreported. ${ }^{1-3}$ On the other hand, undue anxiety about the problems may deter clinicians from requesting investigations. How great are the hazards, and what can be done to reduce them?

Many radiopharmaceuticals may be detected in breast milk. ${ }^{45}$ These substances differ from other drugs in that for diagnostic purposes they are used in tracer quantities and do not produce demonstrable pharmacological changes in the mother or infant. Patients may also be given non-radioactive drugs to induce changes in the distribution of the radiopharmaceuticals, and some of these, too, appear in milk. ${ }^{6-8}$ Drugs used in this way include frusemide, potassium perchlorate, iodides, and cholecystokinin. Iodides are selectively concentrated in breast milk, and some consider them contraindicated during lactation. ${ }^{4}$ Assessment of risks from the other agents is difficult because of lack of data, though the amounts of frusemide that appear in milk seem unlikely to be pharmacologically important..$^{49}$

The more obvious topic of concern is with radiation, which may be transmitted directly from the mother when cuddling and at feeding or be ingested in the milk. There are no standards for evaluating a radiation hazard specifically in infants. The measures used in practice are the dose equivalent limit ${ }^{10}$ and one tenth of the annual limit of intake, corrected for the infant's weight or surface area. ${ }^{11}$ Despite the obvious importance of transmitted radiation there are no relevant data. A recent report of radiation protection procedures for compounds containing technetium-99m concluded that an infant is unlikely to receive transmitted radiation in excess of the dose equivalent limit from a single investigation, though repeated investigations could result in this concentration being exceeded if no advice was given to the mother. ${ }^{12}$

The importance of ingestion hazards was recognised when high concentrations of iodine-131 were measured in the milk of patients undergoing thyroid uptake studies, ${ }^{13-15}$ and was confirmed for iodinated compounds used for other investigations. ${ }^{216-18}$ This selective uptake may result in iodine concentrations in milk being 40 times those in plasma. ${ }^{13}$ Iodides, and probably potassium perchlorate, administered to block the maternal thyroid, will also appear in milk, however, and modify the dose to the infant. ${ }^{26-8}{ }^{99} \mathrm{~m} T \mathrm{c}$ compounds are now the most widely used radiopharmaceuticals, and of these sodium pertechnetate has the highest excretion in milk. ${ }^{3}{ }^{12} 18-22$ The quantity excreted varies with other technetium compounds ${ }^{121823-29}$ and is lowest with ${ }^{99} \mathrm{~m}$ T-diethylenetriaminepenta-acetic acid, which is rapidly excreted by the kidneys. ${ }^{12} 29$ These differences are big enough to be important: with pertechnetate one tenth of the annual limit of intake could be exceeded in certain circumstances with a single feed, ${ }^{12}$ whereas this concentration would not be approached when conventional doses of ${ }^{99 \mathrm{~m}} \mathrm{Tc}$-macroaggregated albumin or ${ }^{99 m}$ Tc-diethylenetriaminepenta-acetic acid were used even with uninterrupted feeding. Other radiopharmaceuticals show wide variation in the amount excreted in milk ${ }^{30-33}$; of particular note is the high content of gallium-67 citrate, probably because of its affinity for lactoferrin..$^{34-38}$

Evaluation of the risk from ingested milk is complicated by several factors. Nearly all the available data take the form of case reports, and for some compounds no such reports are available. Excretion in breast milk shows wide biological variation, ${ }^{13}{ }^{16}$ and most of the studies have been conducted on milk expressed by a breast pump, which may not accurately reflect suckling. The chemical forms of radioisotopes in milk may not be known. Dosimetric calculations of ingested activity extrapolated from adult data have to rely on large assumptions.

Nevertheless, much can be done to reduce radiation to infants. Firstly, the clinician must be sure that the investigation is essential: a basic principle of radiation protection is to avoid unnecessary tests, and this rule needs to be applied rigorously to the nursing mother. On occasions the doctor may not know that a patient is nursing or has young children: signs should be displayed in the waiting areas of diagnostic departments requesting these mothers to identify themselves. The dose should be reduced to the minimum compatible with obtaining a diagnostic result. Sometimes the radiopharmaceutical may be changed to one with less concentration in milk or with other, more favourable dosimetric properties. Examples include the use of ${ }^{99 \mathrm{~m}} \mathrm{Tc}$-diethylenetriaminepentaacetic acid instead of pertechnetate or gluconate for brain scanning, ${ }^{29}$ indium-111 labelled leucocytes instead of ${ }^{67} \mathrm{Gaci}-$ trate for localising pus, ${ }^{33}$ and the substitution of ${ }^{123} \mathrm{I}$ for ${ }^{131} \mathrm{I}$.

A period of interruption of breast feeding, expression of milk, and reduction of close contact with the infant is usually recommended for mothers who have a nuclear medicine investigation. The inconvenience and disadvantages of interrupting breast feeding have to be balanced against the 
potential risk to the infant: the prolonged interruption of feeding advocated for some agents is often impracticable. ${ }^{34} 37$ Interruption for 24 hours (as recommended by some authors) for ${ }^{99 \mathrm{~m}} \mathrm{Tc}$ compounds is excessive for doses used in Britain. Twelve hours leaves a wide range of safety for pertechnetate. No interruption is needed for ${ }^{99 \mathrm{~m}} \mathrm{Tc}$-macroaggregated albumin and ${ }^{99 m} \mathrm{Tc}$-diethylenetriaminepenta-acetic acid in order to remain below one tenth of the annual limit of intake-but in practice mothers are often reassured by a short interruption. ${ }^{39}$ When an investigation is needed for which no data on breast milk secretion are available the mother should be advised to stop breast feeding until measurements made on the expressed milk show it safe to resume.

The list of problems is long, but in practice the risk to the infant is small from most radiopharmaceuticals now in use. Simple precautions will allow most investigations to be performed with little inconvenience. The recommended precautions must err on the side of safety, but as more information becomes available such advice should be able to become less restrictive, particularly with regard to interruption of breast feeding.

A J COAKLEY

Consultant in nuclear medicine

P J MOUNTFORD

Principal physicist

Department of Nuclear Medicine,

Kent and Canterbury Hospital,

Canterbury CT1 $3 \mathrm{NG}$

1 Nurnberger CE, Lipscomb A. Transmission of radioiodine $\left(\mathbf{I}^{131}\right)$ to infants through human maternal milk: JAMA 1952;150:1398-400.

2 Bland EP, Crawford JS, Docker MF, Farr RF. Radioactive iodine uptake by thyroid of breast-fed infants after maternal blood-volume measurements. Lancet 1969;ii:1039-41.

3 Rumble WF, Aamodt RL, Jones AE, Henkin RI, Johnston GS. Accidental ingestion of ${ }^{99 \mathrm{~m}} \mathrm{Tc}$ in breast milk by a 10-week-old child. I Nucl Med 1978;19:913-5.

4 Catz CS, Giacoia GP. Drugs and breast milk. Ped Clin N Am 1972;19:151-66.

5 Anderson PO. Drugs and breast feeding. Drug Intell Clin Pharm 1977;11:208-23.

6 Veall N, Smith T. Excretion of I-125 in breast milk following administration of labelled fibrinogen. Br F Radiol 1980;53:512-3.

Bowring CS, Ormsby PL, Keeling DH. Excretion of I-125 in breast milk following administration of labelled fibrinogen. Br f Radiol 1980;53:513.

8 Siddiqui AR. Accidental ingestion of ${ }^{99} \mathrm{~m}$ Tc in breast milk by a 10 -week-old child. $\mathcal{F}$ Nucl Med 1979;20:799.

9 Lewis PJ, Hurden EL. Drugs in breast feeding. In: Hawkins DF, ed. Drugs in pregnancy. Edinburgh: Churchill Livingstone, 1983:218.

10 International Commission on Radiological Protection. Recommendations of the International Commission on Radiological Protection. Oxford: Pergamon Press, 1977. (ICRP publication 26.)

11 International Commission on Radiological Protection. Limits of intakes of radiomuclides by workers. Oxford: Pergamon Press, 1980. (ICRP publication 30 [suppl to part 2].)

12 Hospital Physicists' Association. Radiation protection procedures in the use of ${ }^{99} \mathrm{~m} T \mathrm{c}$. London: Hospital Physicists' Association. Radiation protection procedures in
Hospital Physicists' Association, 1984:8. (Topic Group report 39.)

13 Honour AJ, Myant NB, Rowlands EN. Secretion of radioiodine in digestive juices and milk in man. Clin Sci 1952;11:447-62.

14 Miller H, Weetch RS. The excretion of radioactive iodine in human milk. Lancet 1955; ii: 1013.

15 Weaver JC, Dobson RL. Excretion of radioiodine in human milk. FAMA 1960;173:872-5.

16 Karjalainen P, Penttila IM, Pystynen P. The amount and form of radioactivity in human milk after lung scanning, renography and placental localization by I-131 labelled tracers. Acta Obstet Gynecoi Scand 1971;50:357-61.

17 Palmer KE. Excretion of $\mathrm{I}-125$ in breast milk following administration of labelled fibrinogen. $\mathrm{Br} \mathcal{F}$ Radiol 1979;52:672-3

18 Wyburn JR. Human breast milk excretion of radionuclides following administration of radiopharmaceuticals. 7 Nucl Med 1973;14:115-7.

19 Spencer RP, Cornelius EA, Kase NG. Breast secretion of ${ }^{99} \mathrm{~m}^{\prime} \mathrm{Tc}$ in the amenorrhea-galactorrhea syndrome. I Nucl Med 1970;11:467.

20 Vagenakis AG, Abreau CM, Braverman LE. Duration of radioactivity in the milk of a nursing mother following ${ }^{99}{ }^{\circ} \mathrm{C} c$ administration. F Nucl Med 1971;12:18.

21 Pittard WB, Bill K, Fletcher BD. Excretion of technetium in human milk. Pediatrics 1979;94: 605-7.

22 Ogunleye OT. Assessment of radiation dose to infants from breast milk following the administration of ${ }^{49} \mathrm{~m} T \mathrm{C}$ pertechnetate to nursing mothers. Health Phws 1983;45:149-51

23 Berke RA, Hoops EC, Kereiakes JC, Saenger EL. Radiation dose to breast-feeding child after miother has ${ }^{99 m}$ Tc-MAA lung scan. F Nucl Med 1973;14:51-2.

miother has
24 Tribukait B, Swedjemark GA. Secretion of ${ }^{99 \mathrm{~m}} \mathrm{Tc}$ in breast milk after intravenous injection of

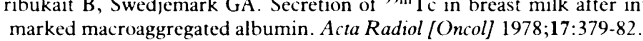

25 Heaton $B$. The build up of technetium in breast milk following the administration of ${ }^{99} \mathrm{~m} T$ c labelled macroaggregated albumin. Br f Radiol 1978;52:149-50.

26 Pittard WB, Merkatz R, Fletcher BD. Radioactive excretion in human milk following administration of technetium ${ }^{9 \% m} \mathrm{Tc}$ macroaggregated albumin. Pediatrics 1982;70:231-4.

27 Mountford PJ, Hall FM, Wells CP, Coakley AJ. Breast-milk radioactivity after a Tc-99m DTPA aerosol Tc-99m MAA lung study. F Nucl Med i984;25:1108-10.

28 O'Connell EA, Sutton H. Excretion of radioactivity in breast milk following ${ }^{99 \mathrm{~m}} \mathrm{Tc}-\mathrm{Sn}$ polyphosphate. Br. F Radiol 1976;49:377-9.

29 Mountford PJ, Coakley AJ, Hall FM. Excretion of radioactivity in breast milk following injection of ${ }^{99 \mathrm{~m}} \mathrm{Tc}$-D TPA. Nuclear Medicine Communications (in press).
.

30 Pullar M, Hartkamp A. Excretion of radioactivity in breast milk following administration of an indium-113m labelled chelate complex. Br F Radiol 1977;50:846.
31 Taylor DM, McCready VR, Cosgrove DO. The transfer of L-selenomethionine-Se-75 to human milk and the potential radiation dose to a breast-fed infant. Nuclear Medicine Communicatio 1981;2:80-3.

32 Mountford PJ, Wells CP, Hall FM, Coakley AJ. Potential radiation dose to a breast-fed infar following administration of sodium P-32 phosphate to the mother. Nuclear Medicine Conf munications 1984;5:473-6.

33 Mountford PJ, Coakley AJ. Excretion of radioactivity in breast milk after an In-111 leucocyte scan. $\mathcal{F}$ Nucl Med (in press).

34 Greener AW, Conte PJ, Steidley KD. Update on gallium- 67 concentration in human breast mil f Nucl Med 1970;11:171-2.

35 Larson SM, Schall GL. Gallium 67 concentration in human breast milk. JAMA 1971;218:257. D 36 Fogh J. Gallium-67 accumulation in malignant tumors and in the prelactating or lactating breases Proc Soc Exp Biol Med 1971;138: 1086-90.

37 Tobin RE, Schneider PB. Uptake of Ga-67 in the lactating breast and its persistence in milk. Nucl Med 1976;17:1055-6.

38 Stepanas AV, Maisey MN. Hyperprolactinaemia as a cause of gallium-67 uptake in the breast. $B r$ Radiol 1976;49:379-80.

39 Langmead WA, ed. Radiation protection of the patient in nuclear medicine. Oxford: Oxfot University Press, 1983.

\section{New and old thoughts on migraine}

In 1944 Professor Aristides Leâo discovered that an electricadi depression spreads across the exposed cortex of the brair when stimulated by touch, pricking, or putting potassium oof the surface. These stimuli provoke a band of electrical silence that travels across the cortex at a rate of $2 \mathrm{~mm}$ a minute and isi accompanied by diminished blood flow. The excitatoro phase is followed by greatly increased pial blood flow, though the brain does not return to normal for a further hour. The possibility that this spreading depression of Leâo might be linked with the migrating visual migraine aura was suggested. by Lashley a few years after its discoverer had written up his findings. Leâo was one of 550 from 35 countries who attended the Second International Headache Congress held in Copenhagen this summer. The British contingent of 4 互 included Dr Marcia Wilkinson, who was elected president of the society for the next two years-a well deserved honour foo years of endeavour in migraine.

Leâo's cortical depression has returned to the centre of thêे stage with more recent work by two Danish workers, Olese and Lauritzen, who have shown a spread of diminished cerebral blood flow in patients with classical migraine. Is this the answer we have been waiting for to solve the problem of migraine? There are similarities between Leâo's animał model and clinical migraine but also important differences For example, there is no vasodilatory phase in the humai observations, and the diminished blood flow outlasts the symptoms of the aura. Leâo's spreading depression cannos account for the headache. Nevertheless, the blood flover findings suggest that the main manifestations of the migraine may well be situated in the brain primarily and not resue. from vascular changes which could be secondary.

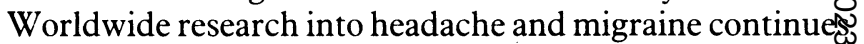
to flourish as treatment follows the vagaries of fashion. $\mathrm{A} \Phi$ present $\beta$ blockers and calcium channel blockers seem to be the mainstay of prophylaxis against migraine, while ergotamine seems to be on the way back for aborting the attacks when they occur. The International Headach Society, founded only two years ago, has formed stud\% groups including those dealing with classification, drue trials, and education and some of the fruits should be ripening by the next international meeting in Florence two years hence.

Consultant Neurologist,

J N BLA

National Hospital

London WC1N 3BG 